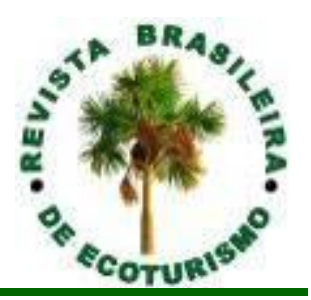

\title{
Projeto 'Rotas da Mata Atlântica': uma proposta de ecoturismo urbano no Campus I da Universidade Federal da Paraíba
}

\author{
Project 'Rotas da Mata Atlântica': a proposal for urban \\ ecotourism in Campus I of the Federal University of Paraíba \\ (PB, Brazil)
}

Diôgo da Silva Santos, Ligia Maria Tavares da Silva

\begin{abstract}
RESUMO: Este presente estudo objetivou apresentar o Ecoturismo Urbano, considerado um novo segmento do ecoturismo que possui grandes possibilidades de sua prática no Brasil, devido à rica diversidade de ecossistemas encontrados no país. Esta atividade vislumbra a prática convencional do ecoturismo também em ambientes urbanos modificados, através de seus espaços verdes, tais como parques, praças e jardins públicos. A partir deste parâmetro, a pesquisa buscou analisar a prática desta atividade no Brasil, em especial, nos parques urbanos inseridos no bioma Mata Atlântica, trazendo o exemplo da gestão dos parques de São Paulo. Com este relatório, analisou-se de que forma o Campus I da Universidade Federal da Paraíba (UFPB), por meio das ações realizadas pelo 'Rotas da Mata Atlântica', projeto este que visa a valorização da Mata Atlântica encontrada no Campus, por meio da estruturação de rotas de pedestres e placas de sinalização ambiental, pode contribuir com a realização do ecoturismo urbano na cidade de João Pessoa. O trabalho foi realizado com base em um levantamento bibliográfico sobre o tema, bem como através de visitas in loco aos parques de São Paulo, nas áreas verdes de João Pessoa e no Campus I da UFPB, objeto de estudo desta pesquisa. Concluiu-se que o Campus I da UFPB possui grande potencialidade em desenvolver a prática do ecoturismo urbano em suas dependências, se tal atividade for bem planejada e estruturada de uma maneira sustentável e em equilíbrio com o meio ambiente.
\end{abstract}

PALAVRAS-CHAVE: Ecoturismo Urbano; Mata Atlântica; Campus I da UFPB; Rotas da Mata Atlântica. 


\section{ABSTRACT}

This present study aims to address the Urban Ecotourism, considered a new segment of ecotourism that has great possibilities of their practice in Brazil, due to the rich diversity of ecosystems found in the country. This activity envisages the conventional practice of ecotourism also in modified urban environments, through its green spaces such as parks, squares and public gardens. From this perception, the research sought to examine the practice of this activity in Brazil, especially in urban parks inserted in the Atlantic Forest biome, bringing the example of the management in parks of São Paulo. With this report, the present study analyzed how the Campus I of the Universidade Federal da Paraíba (UFPB), through the actions carried out by the 'Rotas da Mata Atlântica', a project aimed at the appreciation of the Atlantic Forest found in the Campus, through structuring pedestrian routes and environmental signage boards, and how it can contribute to the achievement of urban ecotourism in the city of João Pessoa. The study was based on literature on the subject, and also through on-site visits in the parks of São Paulo, in the green areas of João Pessoa and on Campus I of UFPB, study object of this research. It was concluded that the Campus I of UFPB has great potential to develop the practice of urban ecotourism in its facilities, if such activity is well planned and structured in a sustainable way and in harmony with the environment.

KEYWORDS: Urban Ecotourism; Atlantic Forest; UFPB Campus I; Rotas da Mata Atlântica.

\section{Introdução}

O turismo mundial vem passando atualmente por grandes modificações no que diz respeito aos desejos dos turistas por novas experiências socioambientais que enriqueçam a sua viagem. E nesta perspectiva que nasce o ecoturismo urbano, um novo segmento do turismo que objetiva a realização da atividade rotineira do ecoturismo em ambientes urbanos e modificados. Dessa forma, as áreas verdes, tais como parques, praças, jardins públicos, florestas urbanas, etc., se transformam em grandes atrativos turísticos e os turistas utilizam essas áreas para obterem um maior contato com a natureza e com a própria comunidade, vislumbrando lazer, bem-estar e qualidade de vida.

O ecoturismo urbano é um segmento originário e bastante divulgado na América do Norte, sobretudo no Canadá, bem como em algumas cidades da Europa (DODDS; JOPPE, 1998). Porém no Brasil ainda é pouco explorado. São Paulo, localizada na região sudeste do Brasil, considerada a cidade brasileira mais influente no cenário global, conta com uma política de planejamento e gestão de parques urbanos e áreas verdes relativamente eficientes. A grande metrópole brasileira conta com diversos espaços públicos de lazer, espalhados por todas as regiões da cidade, que garantem o lazer e o bem-estar de seus citadinos e visitantes (SÃO PAULO, 2012).

Foi a partir desse fato que surgiu a motivação pessoal da pesquisa, ou seja, investigar o ecoturismo urbano no país, em especial, na cidade de João 
Pessoa, localizada na região nordeste do Brasil, a partir da participação em um projeto de extensão realizado no Campus I da Universidade Federal da Paraíba (SILVA, 2014). Buscou-se nesta pesquisa aprofundar os conhecimentos sobre a relação entre turismo e bem-estar, nas áreas verdes inseridas em ambientes urbanos modificados, e de que forma ele pode ser realizado também na cidade de João Pessoa.

Inserida no bioma Mata Atlântica, João Pessoa é uma cidade que ainda conta com significativa quantidade de fragmentos florestais deste bioma em seu território, porém grande parte dessas áreas são privadas (JOÃO PESSOA, 2012). Desse modo, fica evidente a importância que se deve dar às áreas verdes públicas da cidade, para manter a qualidade de vida e os serviços ambientais oferecidos pela floresta. Dentre as áreas públicas da cidade, encontramos o Campus I da Universidade Federal da Paraíba (UFPB), inserida no bioma Mata Atlântica, que possui em suas dependências e nas áreas circundantes, relevantes fragmentos florestais.

Através do 'Rotas da Mata Atlântica', projeto que objetiva a valorização da Mata Atlântica no Campus, a partir da elaboração de um roteiro de pedestre para o ecoturismo urbano, nas áreas que circundam os fragmentos florestais, e da criação e implementação de placas de sinalização ambiental em alguns dos espaços de lazer da UFPB, foi criado o seguinte questionamento: de que forma é viável um projeto de ecoturismo urbano para o Campus I da UFPB? Desse modo, esta pesquisa buscou verificar a viabilidade de um atual projeto de ecoturismo para o Campus I da UFPB.

\section{O ecoturismo urbano no mundo: conceitos e definições}

A atividade turística é também um dos privilégios dos grandes centros urbanos. O turismo nas cidades é realizado com o suporte de diversos segmentos, a citar: turismo patrimonial, turismo de negócios, turismo a lazer e etc.

Muitas cidades encontram-se investindo economicamente em novos equipamentos e projetos de revitalização urbana no intuito de tornar as cidades polos de excitação turística. Entretanto, os turistas estão cada vez mais exigentes e detalhistas, procurando por experiências únicas em suas viagens. Nesta perspectiva, outros segmentos do turismo têm aparecido, e um dos novos conceitos emergidos da atualidade, em especial na América do Norte e na Europa, é o chamado ecoturismo urbano.

O ecoturismo urbano é um conceito em desenvolvimento, ao qual abrange a potencialidade do ecoturismo não apenas em áreas naturais remotas, mas também como atividade praticável em áreas urbanas, desde que as condições permitam, através dos espaços públicos de lazer utilizados com frequência pela própria comunidade receptora, como parques, praças, jardins botânicos, jardins públicos, zoológicos, florestas urbanas e demais áreas naturais.

Nesta perspectiva, Western (2002) ressalta que a tendência atual é utilizar o conceito de ecoturismo para designar qualquer grupo remotamente 
ligado à viagens naturais ou culturais. Já Costa (2002) abrange o termo 'ecoturismo' como uma atividade que visa preservação do patrimônio natural ou cultural de uma localidade, portanto, tal atividade poderá ser desenvolvida tanto em áreas naturais, quanto em áreas urbanas. Oliveira (2013) destaca ainda que "a relação entre turismo e meio ambiente ultrapassa os limites do ecoturismo praticado em ambientes naturais" (2013, p.0), ou seja, a proposta é realizar o ecoturismo também nas cidades por meio de atividades deste segmento nos espaços verdes e públicos, com planejamento e estrutura adequada para o desenvolvimento desta.

O ecoturismo tem por essência a admiração e o respeito à natureza, a partir de um turismo ao ar livre. É uma atividade que concilia a interpretação ambiental, a conservação do patrimônio e o bem-estar da população. Este segmento busca trazer ao visitante o aprendizado de manifestações naturais, mediante interações de baixo impacto ambiental, em que a atividade deva estar diretamente relacionada com os princípios da sustentabilidade (MOLINA, 2001).

Costa (2002) enumera algumas características universais deste segmento, destacando que a observação e a apreciação da natureza são os elementos-chaves do ecoturismo, que exigem uma interpretação do meio ambiente vinculada aos elementos da própria educação ambiental, visando o crescimento econômico das comunidades receptoras, o baixo impacto ambiental das áreas naturais, e o intercâmbio ambiental e cultural entre os habitantes locais e os visitantes.

O potencial do ecoturismo urbano passou a ser explorado a partir da década de 1990, quando pesquisadores começaram a considerar que os espaços verdes nas cidades estão cada vez mais escassos. Wu et al. (2010) enfatizam que a importância do desenvolvimento do ecoturismo urbano tem se destacado progressivamente, porém ainda é um conceito em construção, ou seja, ainda não se encontra bem definido. O ecoturismo urbano é nomeado em diversas pesquisas também como turismo verde urbano.

Alguns pesquisadores (ORAMS, 1995; WU et al., 2010) destacam o potencial desta atividade como uma alternativa viável para as cidades, em virtude das maiores facilidades estarem situadas em áreas urbanas, porém tais atividades necessitam de planejamento e gestão adequados, devido à pressão sofrida pelos grandes centros urbanos por conta da presença de turistas e de construções, podendo assim os locais de destinos deste tipo de segmento sofrerem impactos negativos, visto que o ambiente natural nas cidades é limitado, portanto precioso e frágil.

Okech (2009) destaca a importância do ecoturismo urbano na perspectiva dessa atividade possuir potencial para a restauração de locais que antes foram degradados, marginalizados ou destruídos por atividades industriais e comerciais, além de proporcionar também a educação ambiental em massa aos potenciais participantes, devido ao grande número de visitantes aos centros urbanos, que podem adicionar e praticar o ecoturismo urbano à sua programação e à maior facilidade no acesso aos centros urbanos. Oliveira (2013) conceitua, de forma bastante clara, o ecoturismo urbano, como sendo: 
[...] uma forma de trazer as reflexões e atividades que incluem educação ambiental e o fortalecimento das atividades culturais, visando à melhoria da qualidade de vida das comunidades urbanas (OLIVEIRA, 2013, p.4).

Este subsegmento do ecoturismo teve início no Canadá, por intermédio da Associação de Turismo Verde da cidade de Toronto, que o identificou como uma das maneiras mais sustentáveis para se viajar nas áreas urbanas. Esta Associação vem trabalhando desde 1996 na promoção e desenvolvimento do ecoturismo urbano naquela região de Toronto, e tem por missão desenvolver um turismo verde ecologicamente sustentável, adotando a apreciação e respeito às heranças culturais e naturais, além do fortalecimento da economia local e das comunidades. Segundo a própria Associação de Turismo Verde de Toronto, a maior cidade do Canadá se tornou líder em turismo verde urbano, sendo atualmente modelo de desenvolvimento deste segmento no País e nas cidades ao redor do mundo (GTA, 2002).

Em 1996, um estudo realizado pela Associação de Turismo Verde da cidade de Toronto, definiu o turismo verde urbano como sendo:

[...] viajar e explorar dentro e no entorno de uma área urbana que ofereça aos visitantes o aproveitamento e a apreciação das áreas naturais e dos seus recursos culturais, a partir da inspiração à atividades físicas, estimulação intelectual e experiências sociais interativas; promove a saúde ecológica dos citadinos ao incentivá-los a caminhadas, ciclismo, transporte público; promove sustentabilidade econômica local e desenvolvimento comunitário e vitalidade; enfoca na herança e arte local; é acessível e igualitário a todos (Blackstone Corporation, 1996, tradução do autor) ${ }^{1}$.

A partir desta óptica, verifica-se que os roteiros em ecoturismo urbano podem ser realizados por qualquer pessoa, desde visitantes até a própria comunidade local. Nesta perspectiva, Okech (2009) ressalta que os espaços para a realização do ecoturismo em áreas urbanas já são regularmente frequentados pela própria população residente, pois grande parte desses locais são espaços públicos que garantem o lazer e o contato dos citadinos junto à natureza, garantindo bem estar e qualidade de vida aos moradores e visitantes.

Adicionando, Gastal (2001) exemplifica o modelo do plano da cidade de Porto Alegre, cujo documento considera os próprios residentes como turistas, na medida em que eles saem de sua rotina diária de casa e trabalho, para vivenciar outras atividades em sua própria cidade. Para Gastal (2001), este plano da cidade faz parte da realidade dos citadinos em se fazer 
turismo, devido ao sistema de uma cidade encontrar-se tão complexo e em constante modificação, que a própria movimentação na cidade é considerada como um tipo de turismo.

Wu et al. (2010) destacam ainda que a participação da comunidade é o que promove o ecoturismo urbano nestes espaços, pois é a partir da identificação social com o local, que os turistas tendem a visita-lo devido a sua importância e significância cultural e social.

Cianga e Popescu (2013) afirmam que muitos dos espaços verdes que fazem parte de qualquer sistema urbano, tais como parques, jardins botânicos ou zoológicos e florestas urbanas, possuem um papel de proteção e melhoria do padrão de qualidade do meio ambiente nas cidades, além de serem polos de atração tanto para os residentes quanto para todos os tipos de turistas, devido a sua função promotora do ecoturismo urbano, do lazer público e devido a sua herança cultural resguardada nestes espaços.

Em 2004, foi realizado a I Conferência Internacional sobre Ecoturismo Urbano através do $14^{\circ}$ evento da organização planeta.compore-conference, que reconheceu o ecoturismo urbano como uma oportunidade permanente para conservar a biodiversidade e a diversidade social, criar novos empregos e melhorar a qualidade de vida dos citadinos e dos visitantes, promovendo a sustentabilidade.

A Conferência que contou com a participação de algumas ONG's espalhadas pelo mundo, teve como resultado final a elaboração de uma Declaração do Ecoturismo Urbano, disponível na internet, cujo conteúdo propõe algumas ações e metas para o desenvolvimento deste segmento em âmbito local, federal e internacional, tais como restaurar e conservar a herança natural e cultural, maximizar os benefícios locais e engajar a comunidade, além de educar os visitantes e residentes sobre a importância do meio ambiente, dos recursos patrimoniais e sustentabilidade.

Com a Conferência Internacional de Ecoturismo Urbano também foi possível analisar quais são os aspectos necessários para o desenvolvimento deste segmento nos centros urbanos, ou seja, quais são os elementos estruturantes para a prática do ecoturismo urbano nas cidades. Deste modo, esta declaração recomendou a participação das autoridades locais com a sociedade interessada, de modo em que ambas possam trabalhar em conjunto para atingir as medidas ligadas aos aspectos relacionados abaixo:

1) Informação e Comunicação: ao aprimorar os centros de informações turísticas existentes nas cidades com informações sobre o meio ambiente urbano e cultural, promover a interpretação natural e cultural para residentes e visitantes, além da criação e distribuição de mapas verdes.

2) Biodiversidade: ao divulgar a biodiversidade local com o suporte de mostruários, estudos e portfólios disponíveis aos residentes e visitantes.

3) Comunidades: ao incentiva-los a lutarem pelo uso livre dos espaços públicos, encorajando a participação de pequenos empresários que possuem visão de meio ambiente sustentável, incentivando as 
conexões entre a indústria do turismo e o patrimônio cultural e ambiental das cidades, etc.

4) Energia: ao encorajar a utilização de fontes de energia renováveis.

5) Financiamento: ao adequar a infraestrutura urbana e os espaços públicos para o desenvolvimento organizado do ecoturismo urbano.

6)Transportes: ao estimular residentes e visitantes a utilizarem transporte público, tais como metrôs e trens, além de bicicleta e roteiros de pedestres.

No Brasil, como roteiro de ecoturismo urbano em ascensão, temos São Paulo, considerada a cidade brasileira mais influente no cenário global e que conta com população estimada em mais de 10 milhões de pessoas, que vem desde 2005 seguindo um caminho compatível com a proposta da ONU, na Eco-92, de incorporar o desenvolvimento sustentável como uma diretriz básica de seu planejamento urbano.

Uma das ações que coloca a cidade de São Paulo em destaque na questão da sustentabilidade no Brasil e no mundo é o desenvolvimento do Programa 100 Parques para São Paulo, lançado pela Secretaria do Verde e Meio Ambiente no final de 2007 e tem como objetivo aumentar o número de áreas a serem transformadas em parques municipais na capital paulista (SÃO PAULO, 2012).

A implantação de parques e áreas verdes exercem diversas funções, às quais se podem destacar a preservação de fragmentos naturais de mata, conservação e recuperação de corpos d'água, espaços de lazer e entretenimento, pontos de cultura, de mobilização social, de ações socioambientais, além de serem espaços propícios para a prática do ecoturismo urbano.

Na cidade de São Paulo, o ecoturismo urbano é desenvolvido de uma forma mais estruturada, pois a cidade consegue mesclar os elementos estruturantes essenciais para o desenvolvimento do ecoturismo em ambientes urbanos, a exemplo de transportes públicos como metrô, trens e ônibus. Conta ainda com publicações acerca dos parques urbanos, com mapas de localização, placas informativas e sinalização pertinente (Figuras 1 e 2), estimulando assim a utilização de tais espaços. Cabe ressaltar que, comparando as áreas verdes urbanas de João Pessoa e São Paulo, com base nos trabalhos de campo nas duas cidades, a criação de infraestrutura e de estímulo à visitação é fundamental para o ecoturismo urbano. João Pessoa possui vários parques decretados pela municipalidade que se tornaram áreas abandonadas evitadas pela população devido ao caráter de insalubridade e insegurança que elas representam, sem a dotação de infraestrutura e gestão adequadas. 


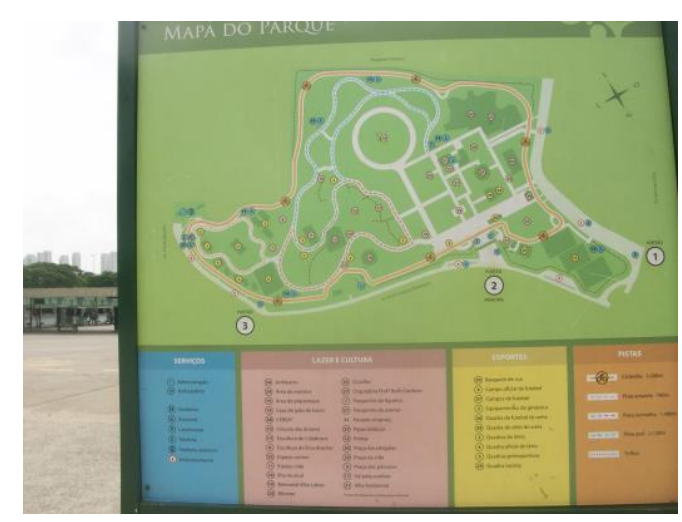

Figura 1: Parque lbirapuera - São Paulo, Mapa de orientação Placa Informativa.

Figure 1: Parque Ibirapuera - São Paulo, Guidance Map Information Plate.

Fonte: Autor, 2014. Source: Author, 2014.

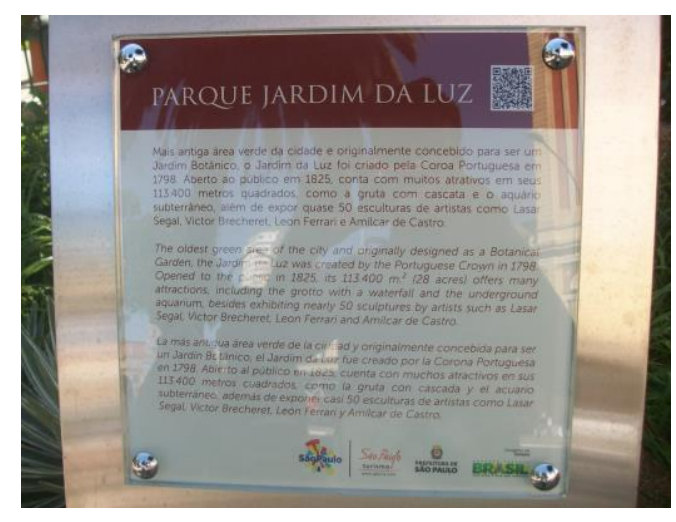

Figura 2: Parque da Luz - São Paulo, Placa. Figure 2: Parque da Luz - São Paulo, Plate. Fonte: Autor, 2014. Source: Author, 2014.

No Brasil, o conceito de parques está associado ao de espaço público, considerado como aquele espaço no território municipal, sendo de uso comum e de posse coletiva, pertencente ao poder público (SILVA, 2012). Estando a criação de parques relacionada à necessidade de encontrar 0 equilíbrio entre a urbanização e a preservação do meio ambiente, os parques e as unidades de conservação são espaços destinados à manutenção dos serviços ambientais na cidade, responsáveis pela prevenção de desastres ambientais como enchentes, deslizamentos de terra, erosão, poluição do ar, da água e do solo, mantendo a biodiversidade, regulando o clima, produzindo oxigênio e água de qualidade. Desta forma, tanto em São Paulo, como em João Pessoa, a criação e manutenção de parques está ao cargo das Secretarias de Meio Ambiente e por isso, os parques seguem as prerrogativas do SNUC - Sistema Nacional de Unidades de conservação, cabendo às municipalidades o estabelecimento dos critérios para a criação e gestão desses espaços verdes públicos, a exemplo dos parques lineares, que vêm restaurando antigos córregos, criando espaços públicos e melhorando a drenagem das águas pluviais na cidade de São Paulo, e recentemente, em João Pessoa. Uma vez planejados e estabelecidos formalmente, de acordo com as categorias estabelecidas na Lei, as áreas protegidas públicas deverão ser geridas pelo Governo Municipal. As unidades de conservação e os parques municipais devem constar, no documento de sua criação, a denominação, as categorias de manejo e uso, os objetivos, os limites e a área territorial, e o órgão responsável por sua administração, contando com um Conselho Gestor para aprovar obras de infraestrutura e quaisquer outras intervenções, a exemplo de espaços culturais e informativos, calendário de eventos e etc. Desta forma, a dotação de infraestrutura ecoturística para o usufruto, o lazer e a educação ambiental (Figuras 3 e 4) deve se dar de acordo com as 
características de cada parque, ou seja, de acordo com os objetivos para os quais foram criados (SILVA, 2012).

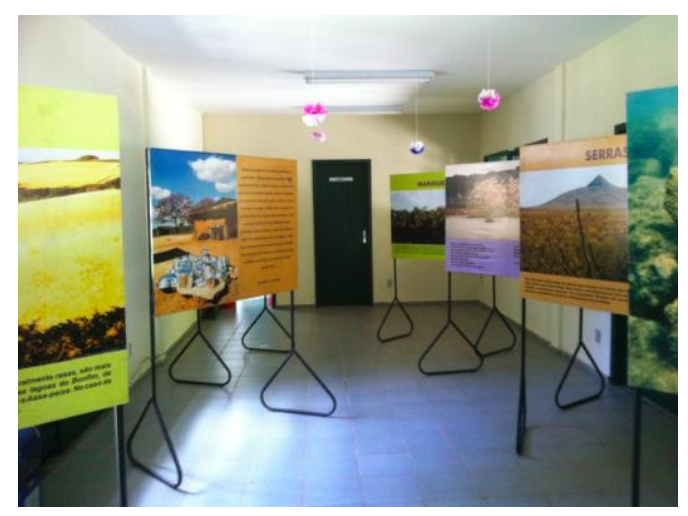

Figura 3: Parque das Dunas - RN, Espaço de Educação Ambiental.

Figure 3: Parque das Dunas - RN,

Environmental Education Space.

Fonte: Autor, 2015. Source: Author, 2015.

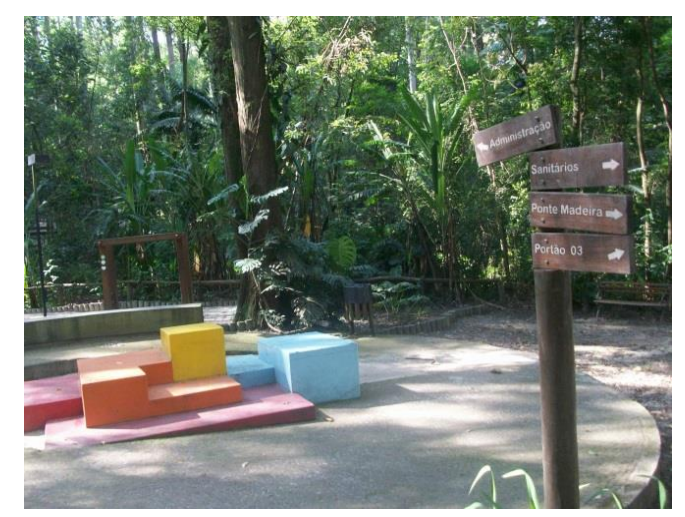

Figura 4: Parque Colinas de São Francisco SP, Espaço de vivências ambientais.

Figure 4: Parque Colinas de São Francisco SP, Space of environmental experiences.

Fonte: Autor, 2014. Source: Author, 2014.

A seguir, iremos verificar de que forma o Campus I da Universidade Federal da Paraíba(UFPB) através do projeto de extensão 'Rotas da Mata Atlântica' pode ser considerado um roteiro viável de ecoturismo urbano para a cidade de João Pessoa.

\section{O Campus I da Universidade Federal da Paraíba}

João Pessoa, capital do Estado da Paraíba, faz parte da mesorregião Zona da Mata Paraibana e da microrregião de João Pessoa, a qual é composta por mais cinco municípios: Bayeux e Santa Rita (com os quais se limita a Oeste), Cabedelo e Lucena (com o qual se limita ao Norte), Conde (com o qual se limita ao Sul).

João Pessoa é a terceira cidade mais antiga do Brasil, fundada em 05 de agosto de $1585 \mathrm{com}$ o nome de Nossa Senhora das Neves, vindo a receber o nome atual apenas no ano de 1930. O município possui uma área total de $211 \mathrm{~km}^{2}$ (0,3\% da superfície do estado da Paraíba), com uma população residente de 723.515 habitantes concentrando-se em área urbana, com $78 \%$ da população.

Localizada na região costeira do estado da Paraíba, João Pessoa encontra-se dentro do domínio Mata Atlântica, mais especificamente formada por um tipo florestal denominado Mata dos Tabuleiros, cuja vegetação é classificada como Floresta Estacional Semidecidual das Terras Baixas (JOÃO PESSOA, 2012).

João Pessoa possui um diferencial perante as outras capitais, pois mantém em sua zona urbana um remanescente vegetal extenso, de 
aproximadamente 515 hectares - a Mata do Buraquinho - classificada como Reserva da Biosfera da Mata Atlântica e recentemente transformada em Unidade de Conservação de Proteção Integral Refúgio de Vida Silvestre (SILVA, 2014).

Segundo dados do Plano Municipal de Conservação e Recuperação da Mata Atlântica, João Pessoa conta com 30,67\% de áreas verdes em seu território, que inclui a Mata Atlântica e seus ecossistemas associados, o que é relativamente positivo. Ademais, dos remanescentes existentes, 85,95\% estão localizados em áreas privadas enquanto que apenas $14,05 \%$ em áreas públicas. Estes dados atestam a importância das áreas verdes públicas para salvaguardar o que restou dos fragmentos de Mata Atlântica no município e sobre a importância da criação de mecanismos institucionais e políticas públicas que visam garantir a permanência desses remanescentes vegetais em áreas estratégicas para a conservação da biodiversidade e da garantia da manutenção dos serviços ambientais.

Dentre as áreas públicas existentes para a conservação do bioma no município, destaca-se a Universidade Federal da Paraíba (UFPB), área específica de nosso estudo, com seus fragmentos de Mata Atlântica no Campus I e no entorno do mesmo, equivalente a 43,70 hectares na área interna do Campus (Figura 5).

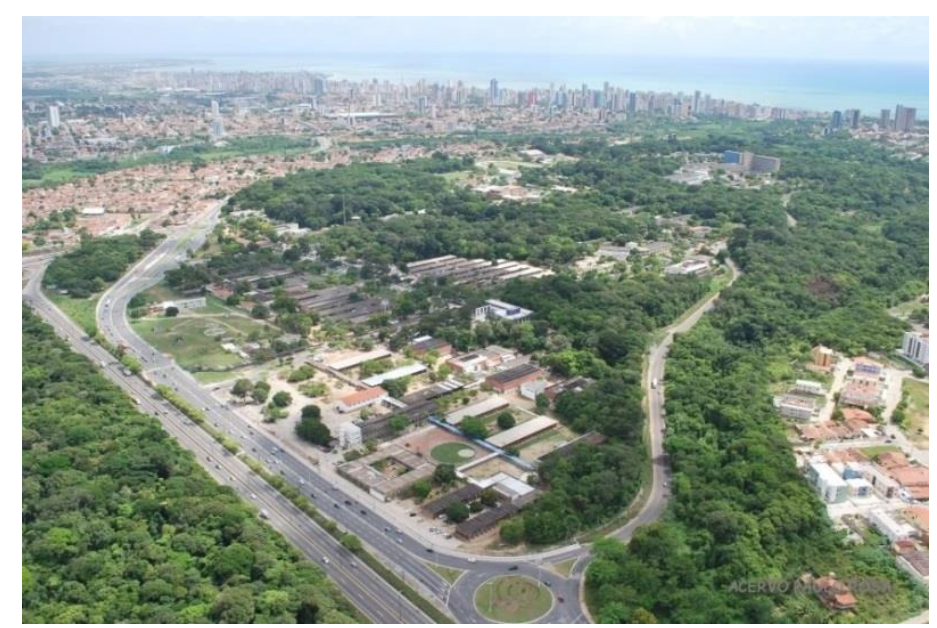

Figura 5: Campus I da UFPB, em João Pessoa - PB.

Figure 5: Campus I of the UFPB, in João Pessoa - PB.

fonte: skyscrapercity.com

Source: skyscrapercity.com

O Campus I da UFPB está situado na malha urbana de João Pessoa, limitando-se ao Norte com o bairro Presidente Castelo Branco, ao Sul com o Vale do riacho Timbó, a Leste com terrenos do estado arrendado ao seminário Arquidiocesano e ao Oeste com a BR-230 e a Mata do Buraquinho e encontra-se inserido na Mata Atlântica e contém tanto em seu entorno, como em suas dependências, significativos fragmentos florestais deste bioma. De acordo com o Atlas Geográfico da UFPB, o Campus ainda conta com 43,98 hectares distribuídos em oito fragmentos internos e 43,70 hectares na área externa, contígua ao campus (NASCIMENTO, 2002; UFPB, 2013). 
A UFPB é considerada um espaço público de convívio e de integração social entre os alunos, por meio de suas salas de aula, dos centros de convivência e das praças espalhadas pelo Campus, entretanto, nos últimos meses, em especial nos finais de semana, vem recebendo visitantes de diversos locais da cidade e de diferentes faixas etárias para a prática de atividades de lazer e integração social em suas dependências: são grupos de patinadores, skatistas e ciclistas, assim como também famílias e cidadãos interessados em estar em contato com a natureza num espaço tranquilo, equipados com segurança e estrutura básica nos finais de semana.

Visto que esta instituição pública ainda possui em suas dependências a presença de fragmentos florestais da Mata Atlântica do município, e que recebe centenas de estudantes e visitantes todos os dias, é essencial que a UFPB, por meio da extensão, também contribua de alguma forma com a formação ambiental de seus frequentadores, por meio de projetos que tenham em sua essência a disseminação da educação ambiental visando a preservação deste bioma tão ameaçado.

Neste sentido, o Projeto de Extensão 'Rotas da Mata Atlântica' no Campus I da UFPB que visa promover a valorização e a conservação da Mata Atlântica por meio da criação de rotas e espaços informativos, é considerado um importante instrumento na luta pela conservação do bioma e da extensão da educação ambiental por diversos níveis sociais, na perspectiva de chamar a atenção dos frequentadores sobre a Mata Atlântica.

Deste modo, iremos nos restringir a este Projeto no próximo tópico, informando os objetivos e as metas alcançadas com esta Extensão, bem como iremos diagnosticar a importância deste Projeto na perspectiva de inserir a UFPB como um roteiro de ecoturismo urbano bem equipado para a realização de caminhadas e a promoção de educação ambiental em meio aos fragmentos de Mata Atlântica encontrados no Campus I da UFPB.

\section{Estudo de caso: Projeto 'Rotas da Mata Atlântica' no Campus I da UFPB}

O 'Rotas' é um projeto de extensão, cujo objetivo principal é o de promover o ecoturismo urbano por meio da valorização e a conservação da Mata Atlântica no Campus I da UFPB.

A proposta deste projeto é informar e estimular a comunidade universitária e adjacente ao Campus I sobre a importância da Mata Atlântica, de modo que eles possam valorizar os fragmentos florestais ainda conservados no campus, por meio da elaboração de rotas e informação visual, estimulando a educação ambiental transversal, oferecendo roteiros estruturados de trabalho de campo nas proximidades da sala de aula. Como adicional, com a concretização deste projeto, será possível utilizar-se deste espaço público como uma área de lazer da cidade nos finais de semana e, com isto, a própria Prefeitura Municipal poderia adicionar em seus roteiros turísticos da cidade, para visitar o Campus I da UFPB, estimulando com isto o Ecoturismo Urbano em João Pessoa. 
O 'Rotas' foi criado pelo Departamento de Geociências - Centro de Ciências Exatas e da Natureza (CCEN), apoiado pela Comissão de Gestão Ambiental e Prefeitura da UFPB, e conta com suporte das seguintes áreas: a Geografia, para observação, pesquisa e interpretação da paisagem; a Comunicação Social, para orientação sobre a comunicação visual para a educação ambiental; a Arquitetura para propor o paisagismo das rotas e espaços de lazer, bem como o design das placas informativas; a Engenharia Ambiental, para propor soluções técnicas e; Turismo, para diagnosticar a viabilização de tal Projeto na perspectiva de torna-lo um produto turístico da cidade de João Pessoa, com enfoque na conservação ambiental por meio do ecoturismo urbano.

Para a viabilidade de execução do Projeto, ficaram decididos os seguintes objetivos específicos: divulgação do projeto em mídias sociais; identificação de rotas cotidianas de pedestre no campus e no entorno; identificação de áreas utilizadas para o lazer pela comunidade universitária; elaboração das rotas a serem diferenciadas demarcadas no campus; a sinalização para a informação ambiental no campus e; divulgação dos resultados parciais.

O primeiro objetivo desenvolvido no projeto foi a divulgação do 'Rotas' nas redes sociais, visando a participação da comunidade universitária no projeto, foi desenvolvida uma ação conjunta ao Facebook, criando perfil e página social, convidando os frequentadores e usuários do Campus I a curtirem a página, alcançando um total de 660 curtidas até o presente momento.

Na ocasião, foram compartilhadas informações sobre a fauna e a flora encontrada no Campus I a partir dos trabalhos de campo desenvolvidos, bem como também é um veículo de denúncias socioambientais, onde as irregularidades visualizadas no Campus são compartilhadas na rede social, tais como lixo irregular próximo aos fragmentos de Mata ou veículos estacionados em locais indevidos.

Como preparação para o desenvolvimento das rotas de pedestres, o mapa temático e as placas de sinalização ambiental, diversos trabalhos de campo na área estudada foram feitos com o intuito de visualizar os espaços mais frequentados pela comunidade acadêmica, bem como quais são os elementos na paisagem que marcam as rotas encontradas no campus I que circundam os fragmentos florestais do local.

\section{Mapa temático do 'Rotas'}

A partir da identificação, por meio de trabalho de campo, destes percursos cotidianos da comunidade universitária e de seu entorno, teve início o desenvolvimento das rotas cotidianas de pedestres através da cartografia. Este foi o passo inicial por onde começou a ser desenvolvido o mapa temático das rotas de pedestre, um dos objetivos principais do Projeto. Ademais, o trabalho de campo também foi ideal para descobrir as áreas de lazer próximas aos fragmentos de Mata Atlântica que poderiam ser, futuramente, contempladas com as placas educativas que promovem a conscientização ambiental no campus. 
Após o diagnóstico das áreas de lazer do Campus I, os monitores do projeto desenvolveram a cartografia das áreas de socialização da UFPB para o incremento do mapa temático, onde foi diagnosticado 08 espaços de lazer para a elaboração do mapa, a citar: Coreto do Departamento de Educação Física; Bosque do CCS - Centro de Ciências e Saúde; Coreto do CCS; Praça ao lado da Reitoria; Coreto do CCEN - Centro de Ciências Exatas e da Natureza e; Bosque do CA - Central de Aulas.

Além disso, nesta etapa houve também a escolha dos conceitos de design para as rotas. Para a execução destas metas, exemplos de mapas temáticos dos parques urbanos de São Paulo foram utilizados como modelo, devida cidade ser considerada um importante destino de ecoturismo urbano no Brasil.

Ainda na concretização desta meta, a de desenvolvimento do mapa temático do projeto 'Rotas', foi decidido após alguns trabalhos de campo e inúmeras reuniões dos monitores com a coordenadora do Projeto, o título de cada rota mapeada para o Projeto e que seriam utilizadas para a elaboração do mapa temático, a citar: Rota do Sagui; Rota do Bosque; Rota da Chuva; Rota do Por do Sol; Rota das Belas Artes e; Rotas Alternativas (Rota Preguiça Gorda).

Vale ressaltar que o título das respectivas rotas se deu a partir da visitação in loco e da observação da paisagem do Campus I, onde após os trabalhos de campo puderam-se verificar alguns elementos que estavam mais perceptíveis e se destacavam mais na paisagem do que outros.

\section{A sinalização para a informação ambiental no Campus}

Com o mapa temático parcialmente pronto, os monitores do 'Rotas' saíram em trabalho de campo pelas rotas de pedestres já estabelecidas no Campus I da UFPB com o intuito de diagnosticar quais eram os pontos mais relevantes a serem fixadas as placas informativas do Projeto. Assim, optamos por espaços de lazer mais frequentados, pontos estratégicos com maior circulação de pessoas (Figuras 6 e 7, página seguinte).

Após diagnosticado os espaços propícios para a implantação das placas de sinalização ambiental, iniciou o estudo das frases de educação ambiental que estariam nas placas. Para isso, realizou-se um estudo dentro da Comunicação sobre a melhor maneira de disseminar a conscientização ambiental no Campus I da UFPB. Deste modo, optou-se pelo estudo da Educomunicação Ambiental, um novo campo de conhecimento que abrange as ciências da Educação e da Comunicação em prol de uma visão de meio ambiente mais justo, equilibrado, ético e sustentável.

A Educomunicação Ambiental visa a utilização de práticas comunicativas cujo conteúdo possa ser acessado por todos, sem restrição de ideologias. Tais práticas são "comprometidas com a ética da sustentabilidade na formação cidadã, visando à participação, articulação entre gerações, setores e saberes, integração comunitária, reconhecimento de direitos e democratização dos meios de comunicação (PEEA-ES, 2009, 
Art.21)". Ademais, a Educomunicação Ambiental busca o enfoque na comunicação direta e simples, onde qualquer pessoa possa interpretar e se conscientizar a partir da mensagem transmitida.

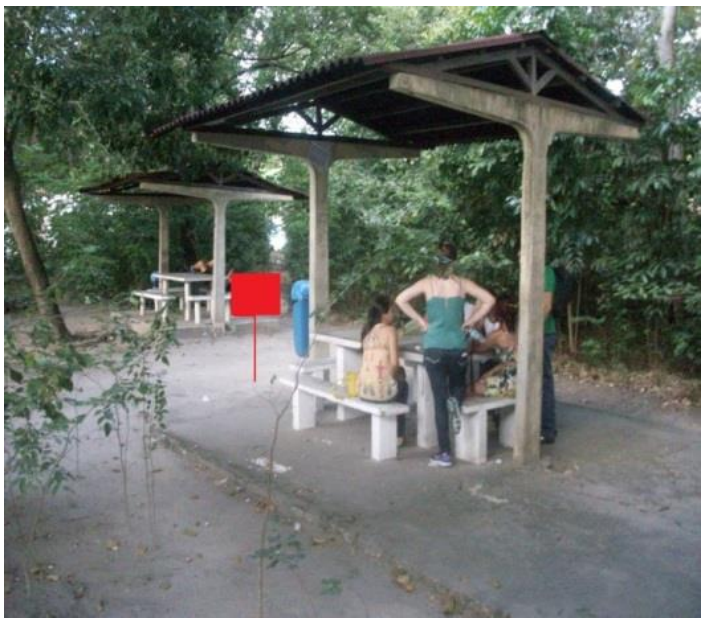

Figura 6: Local de implantação das placas, Bosque do CCS.

Figure 6: Place of implantation of the plates, Forest of CCS.

Fonte: Autor, 2014. Source: Author, 2015.

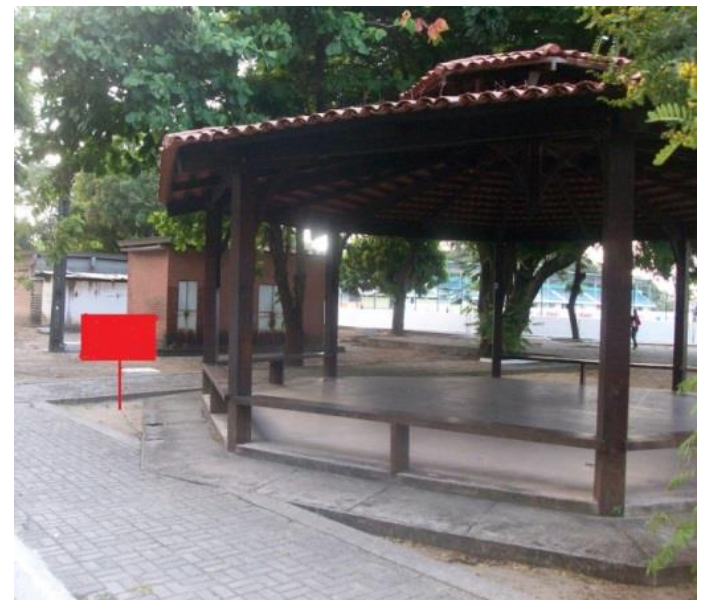

Figura 7: Local de implantação das placas, Coreto da Ed. Física.

Figure 7: Place of implantation of the plates, Physical Education Bandstand.

Fonte: Autor, 2014. Source: Author, 2014.

Nascimento (2010) ressalta que a educomunicação ambiental possibilita a construção do sujeito e da sua relação com o meio ambiente, pois os recursos midiáticos influenciam a tomada de decisão e os conscientizam sobre a percepção do meio.

A criação conceitual dos dizeres das placas foi determinada após diversas reuniões para definirem os principais pontos a serem abordados nas placas e que mais chamariam a atenção do público. Com isto, decidiuse que os temas relacionados à biodiversidade do Campus I, bem como os serviços ambientais oferecidos pelas florestas seriam os pontos norteadores no desenvolvimento do conceito dos dizeres das placas.

Para a concretização e elaboração das frases de efeito que estariam contidas nas placas, foi realizada uma pesquisa junto a livros e anuários da Mata Atlântica que conceituam a definição de serviços ambientais da natureza, assim como em trabalhos científicos feitos por alunos da UFPB que tinham como tema principal a fauna e flora, ou seja, a biodiversidade encontrada no Campus I (SANTOS, 2014; MEDEIROS, 2010). Como resultado parcial, segue a seguir algumas frases criadas que irão compor os dizeres das placas:

Placa I - Coreto da Educação Física/ Fisioterapia - Rota do Sagui "Você está na Rota do Sagui! Este animal, cientificamente conhecido como Callithrixjacchus, pertence ao bioma Mata Atlântica e se adapta muito bem ao meio urbano. No entanto, para garantir a sadia reprodução da espécie, é necessário que os fragmentos de mata atlântica estejam em conexão". 
Placa II - Bosque do CCS - Centro de Ciências da Saúde - Rota do Bosque "Você está na Mata Atlântica! Sinta o clima ameno e a tranquilidade do ambiente. Você sabia que a Mata Atlântica é responsável por regular o clima na nossa cidade? Além disso, a mata ameniza desastres como enchentes, secas e tempestades e filtra o ar poluído. Aqui você respira vida!"

Após o diagnóstico dos espaços de lazer a serem fixados as placas de sinalização ambiental e os dizeres das placas, era necessário a criação do design das placas de sinalização. Para isso, foi discutido quais eram os atuais produtos utilizados na fabricação de placas de sinalização mais resistentes às reações naturais do clima, como a luz do sol ou a chuva, bem como discutíamos a utilização e empresas que trabalhavam com o material menos danoso ao meio ambiente. Após reuniões e debates acerca da criação do design das placas, chegamos ao resultado final (Figura 8), inicialmente da dimensão das placas maiores.
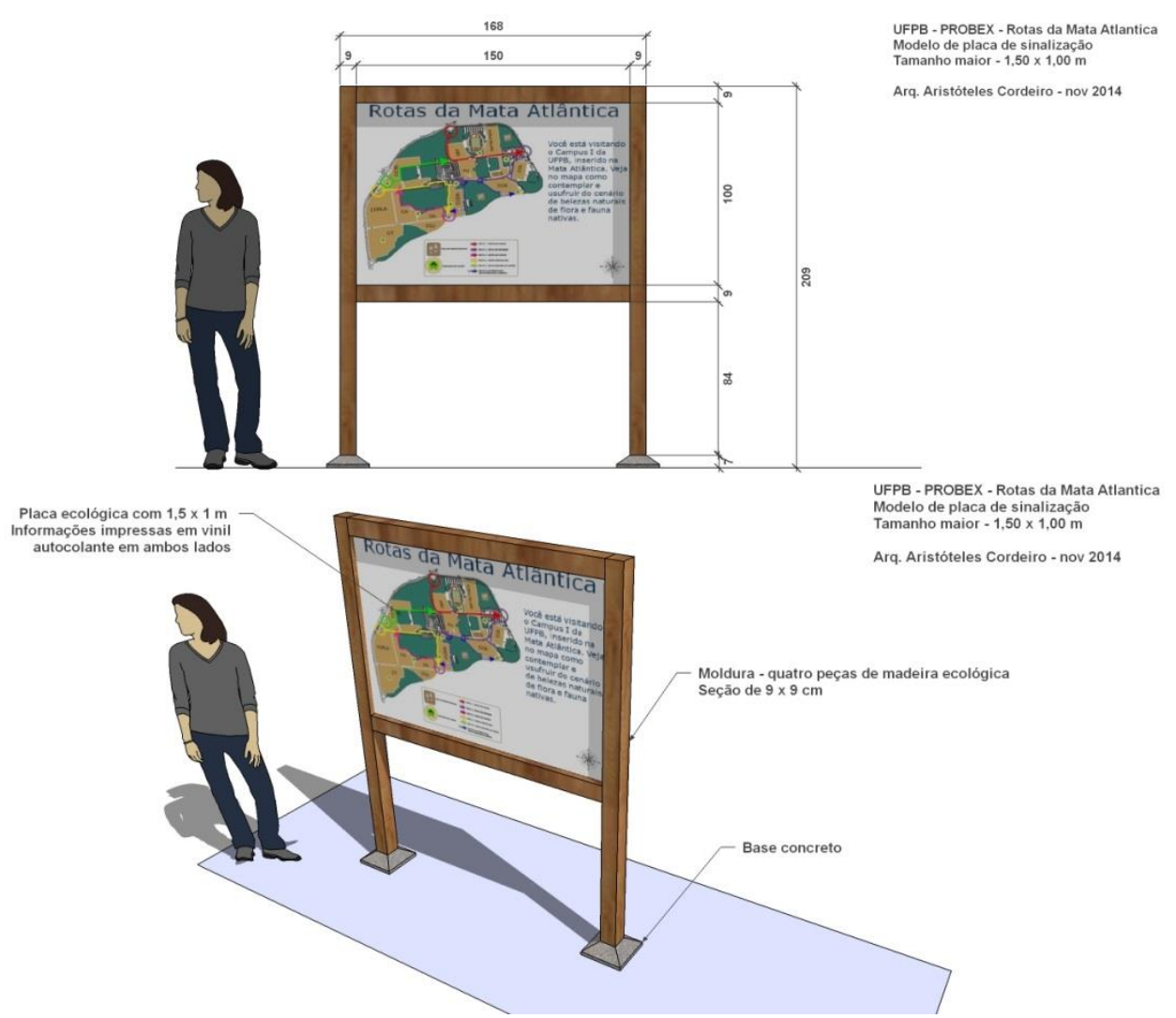

Figura 8: resultado das placas de sinalização - modelo maior do 'rotas'.

Figure 8: results of signal boards - major model of 'rotas'.

Autor: Aristóteles Cordeiro, DAU - UFPB, 2015.

Author: Aristóteles Cordeiro, DAU - UFPB, 2015

Este modelo de placa acima estará distribuído em todos os portões de entrada do Campus I da UFPB, ou seja, nas quatro entradas de veículos, a citar: Portão do CT - Centro de Tecnologia, Portão do CCHLA - Centro de Ciências Humanas, Letras e Artes, Portão Principal - Castelo Branco e Portão da Residência Universitária. 
Foi escolhido este modelo de placa maior para estar nos portões principais da UFPB como uma forma de apresentar aos frequentadores e, em especial, os visitantes, do projeto 'Rotas' e todas as informações sobre o Campus I, pois enquanto na frente o visitante poderá identificar o mapa temático da UFPB, por trás existirá um apanhado de informações sobre o Campus I da UFPB, bem como sobre o Projeto 'Rotas' e os telefones importantes da universidade, tais como a polícia do Campus, o Hospital Universitário e a Reitoria.

A seguir, iremos verificar como ficariam as placas de tamanho menores, espalhadas no decorrer do Campus I da UFPB (Figura 9):

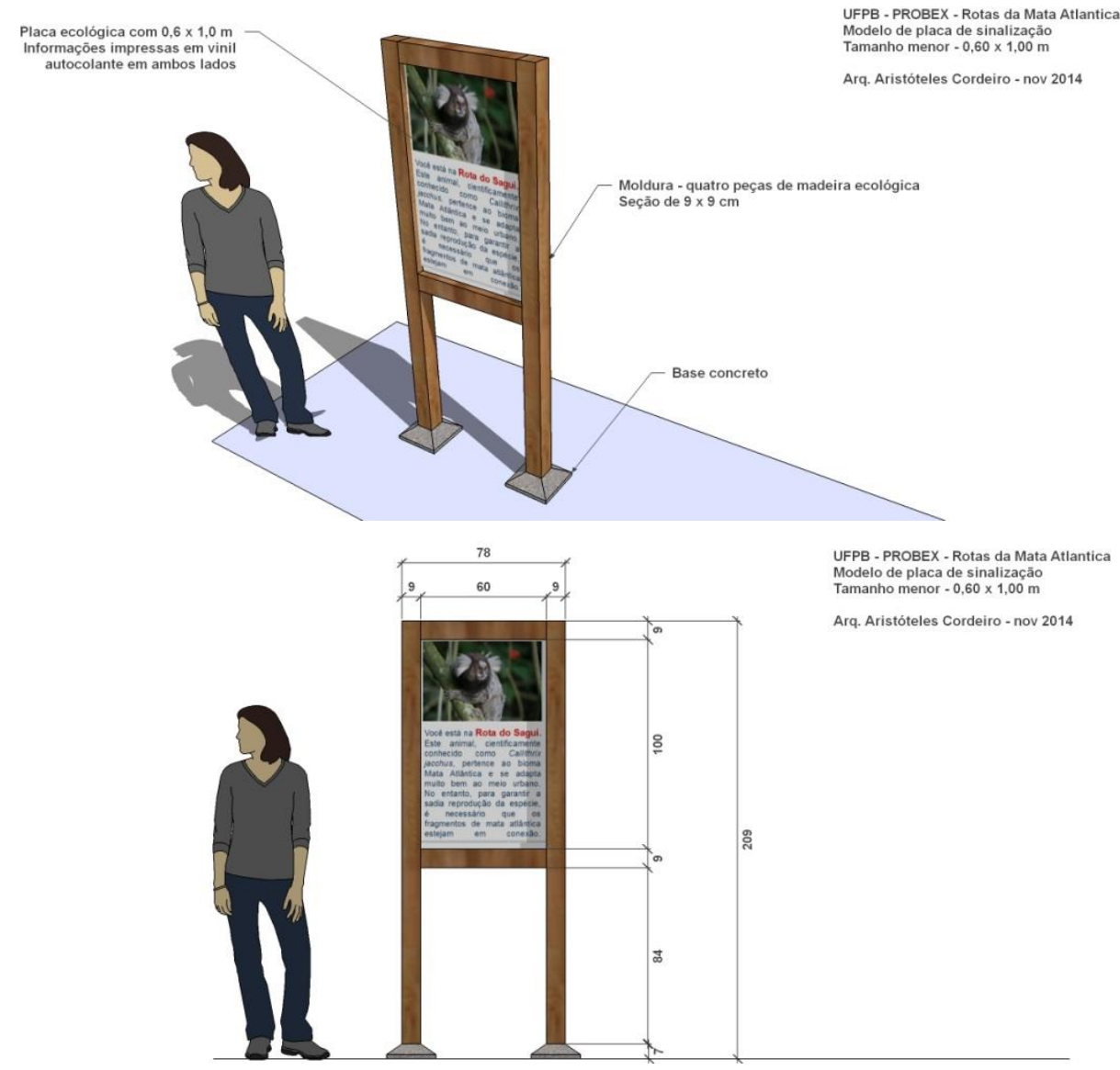

Figura 9: resultado das placas de sinalização - modelo maior do 'rotas'.

Figure 9: results of signal boards - smaller model of 'rotas'.

Autor: Aristóteles Cordeiro, DAU - UFPB, 2015.

Author: Aristóteles Cordeiro, DAU - UFPB, 2015

Como identificado, as placas distribuídas pelo Campus I e que trazem informações sobre a biodiversidade, os serviços ambientais e a história do Campus I da UFPB seriam os principais assuntos abordados nestas placas. Ao todo são 04 placas do tamanho maior e mais dez placas do tamanho menor.

Como resultado final do 'Rotas da Mata Atlântica', além do projeto das placas, foi desenvolvido também o mapa temático do Campus I da UFPB. 
Nele, pode-se visualizar o mapa do Campus I da UFPB de uma maneira dinâmica e lúdica, ou seja, onde qualquer pessoa que tivesse acesso poderia entendê-lo. Encontram-se no mapa temático os fragmentos de mata atlântica do Campus na cor verde, bem como grande parte dos centros de ensino da UFPB e os principais prédios, tais como a Reitoria e a Biblioteca. Além disso, também pode-se vislumbrar as rotas de pedestres nomeadas de acordo com suas características específicas, como também a localização dos espaços de lazer, onde encontram-se as placas de sinalização ambiental.

\section{Considerações finais}

Através do presente estudo, avaliou-se a potencialidade do ecoturismo urbano na cidade de João Pessoa, especificamente no Campus I da UFPB, através do Projeto Rotas da Mata Atlântica. Pela pesquisa, identificamos os pensamentos idealistas que nortearam o surgimento e a prática do ecoturismo em ambientes naturais. Em seguida, definimos o ecoturismo urbano, suas principais características e quais são os locais no Brasil que desenvolvem este tipo de atividade e de que forma a cidade de João Pessoa, em especial, o Campus I da universidade pode trabalhar neste segmento em suas ações sustentáveis.

Diante do exposto neste trabalho, concluímos que o Campus I da UFPB por meio deste projeto, é um relevante espaço público para a iniciação da prática do ecoturismo urbano na cidade de João Pessoa, cuja contribuição do projeto visa conscientizar a comunidade acadêmica e os visitantes do campus acerca da importância da Mata Atlântica.

Além do mais, verificamos também que o Campus I encontra-se equipado com os elementos estruturadores do ecoturismo urbano, ou seja, se a atividade for bem planejada, a instituição de ensino também poderá ser considerada um roteiro de ecoturismo urbano no Brasil. Isto se dá principalmente quanto aos seguintes aspectos:

- Devido à fácil localização, pois a universidade encontra-se numa área central da cidade, dispõe de transporte público eficaz com diversas linhas de ônibus circulando nas mediações do campus;

- Dispõe de estrutura básica, oferecendo sanitários, bebedouros, lanchonetes, segurança, ruas calçadas, praças e espaços de lazer, e etc.;

- Possui significativos fragmentos florestais dentro e ao redor do Campus, contendo rica biodiversidade de fauna e flora;

- Possui uma Comissão de Gestão Ambiental que gerencia toda a questão ambiental do Campus I, encorajando energias renováveis e promovendo práticas sustentáveis.

A partir da concretização do Projeto 'Rotas', a universidade poderá vir a ser considerada um relevante espaço público próprio para a realização de 
atividades relacionadas ao ecoturismo urbano e ao lazer, sendo reconhecida também como um local público de interação e responsabilidade ambiental junto à natureza, em especial a Mata Atlântica. Poderá ser vista ainda como um espaço de lazer da comunidade, onde a mesma poderá usufruir-se nos finais de semana para a prática de atividades físicas e de lazer, gerando com isto, mais bem-estar e mais qualidade de vida aos moradores circundantes da universidade.

Ademais, o ecoturismo urbano será possível também na medida em que a informação e divulgação sobre o 'Rotas' tomar novos destinos, ou seja, cidadãos que antes não conheciam a universidade por algum motivo específico, passarão a ter curiosidade em visita-la, e a partir daí estas pessoas ainda residentes da cidade serão o que Gastal (2001) considera como turistas em sua própria cidade. Esta recente linha de pensamento leva em consideração que os deslocamentos nos centros urbanos se encontram tão complexos que são considerados quase como os deslocamentos realizados entre regiões.

Do mesmo modo, sabendo que o ecoturismo urbano, por ser uma atividade que visa a integração social e a educação ambiental, nos leva à concluir que o Projeto 'Rotas da Mata Atlântica no Campus I' é um importante instrumento de conscientização e de valorização dos fragmentos florestais e da biodiversidade encontrada na natureza, bem como também um relevante disseminador da prática do ecoturismo em ambientes urbanos, na medida em que os elementos estruturadores desta atividade sejam enfim planejados e gerenciados no Campus I da UFPB.

Concluímos, portanto, que ao abordar o ecoturismo urbano, um tema ainda pouco discutido na academia em âmbito nacional e destrinchar os aspectos históricos que circundam esta atividade, a presente pesquisa traz uma contribuição bastante significativa para este segmento que aos poucos está tomando forma no Brasil, pois apresenta o ecoturismo urbano, suas principais características e elementos estruturadores, além de alguns exemplos de prática desta atividade, podendo esta pesquisa ser utilizada, inclusive, como base para futuros trabalhos na área do ecoturismo urbano no Brasil.

\section{Referências}

BLACKSTONE CORPORATION. Developing an urban ecotourism strategy for metropolitan Toronto: A feasibility assessment for the green tourism partnership. Toronto: Toronto Green Tourism Association, 1996.

CIANGA, N.; POPESCU, A.C. Green spaces and urban tourism development in Craiova Municipality in Romania. European Journal of Geography, v.4, issue 2: 34-45, 2013.

COSTA, P.C. Unidades de conservação: matéria-prima do ecoturismo. São Paulo: ed. Aleph, 2002.

DODDS, R. JOPPE, M. Urban Green Tourism: Applying ecotourism principles to the city. Traveland Tourism Research Association - Canada. Toronto, Canada: October 4-6, 1998. 
GASTAL, S. O produto cidade: caminhos de cultura, caminhos de turismo. In: Castrogiovanni, A.C. (Org.). Turismo urbano, 2ª Ed. São Paulo: Contexto, 2001.

GTA. Urban green tourism: industrial and labour market opportunities in the Toronto region. Toronto: Green TourismAssociation, 2002.

JOÃO PESSOA. Plano municipal de conservação e recuperação da Mata Atlântica de João Pessoa. SILVA, L.M.T. (coord.) João Pessoa: Prefeitura Municipal - F\&A Gráfica e Editora, 2012.

MEDEIROS, S.T.A. Proposta para implantação de estruturas para a conexão ecológica entre os fragmentos florestais do Campus I da UFPB e do seu entorno. Trabalho de Conclusão de Curso, Bacharelado em Biologia. João Pessoa: UFPB, 2010.

MOLINA E. S. Turismo e ecologia. Bauru, SP: EDUSC, 2001.

NASCIMENTO, M.O.T. Estudo de temperatura e conforto térmico: o caso da área do Campus I na UFPB. Trabalho de Conclusão de Curso, Bacharelado em Geografia. João Pessoa: UFPB, 2002.

NASCIMENTO, R.F.A. Educomunicação ambiental: um caminho para a sustentabilidade de um bairro. In: Anais do $1^{\circ}$ Encontro de História da Mídia da Região Norte, 2010.

OKECH, R.N. Developing urban ecotourism in Kenyan Cities: a sustainable approach. Journal of Ecology and Natural Environment Vol. 1(1), pp. 001-006, April, 2009.

OLIVEIRA, B.C.S. O Projeto Tartarugas Urbanas - ONG Guajirú: uma alternativa de ecoturismo na Paraíba. Trabalho de Conclusão de Curso, Bacharelado em Turismo. João Pessoa: UFPB, 2013.

ORAMS, M.B. Toward a more desirable form of ecotourism. Tourism Management, 16(1), 3-8, 1995.

PEEA-ES (Política Estadual de Educação Ambiental do Espírito Santo), Lei Estadual no 9.265, de 16 de julho de 2009.

PLANET.COM Urban Ecotourism Declaration. (Primeira Conferência Internacional sobre Ecoturismo Urbano, 2004). Disponível em: < $<$ http://old.planeta.com/ecotravel/tour/urbandeclaration.html> Acesso em: 28.dez.2014.

SANTOS, T.O. Riqueza e status de conservação de espécies no Campus I da UFPB. Trabalho de Conclusão de Curso, Bacharelado em Biologia. João Pessoa: UFPB, 2014.

SANTOS, D.S. O ecoturismo urbano na Mata Atlântica brasileira: um estudo de caso do Projeto 'Rotas da Mata Atlântica' no Campus I da UFPB. Trabalho de Conclusão de Curso, Bacharelado em Turismo. João Pessoa: UFPB, 2015.

SÃO PAULO. Guia dos parques municipais de São Paulo, 3aㅡ. Ed. São Paulo: Secretaria do Verde e do Meio Ambiente, 2012.

SILVA, L. M. T. Espaços Verdes em João Pessoa: Planejamento e Realidade. In: Seabra, Giovanni. (Org.). Terra, Cidades, Natureza e Bem estar. 1ed.João Pessoa: Universitária UFPB, 2012, v. 1, p. 185-200.

SILVA, L.M.T. Rotas da Mata Atlântica no Campus I da UFPB: A Geografia no Cotidiano. Universidade Federal da Paraíba: EDITAL PROBEX UFPB, 2014. 
UFPB. Atlas geográfico da UFPB: planos de informação do Campus I. ROSA, P., ROSA, C. (ORGS). João Pessoa, Editora da UFPB, 2013.

WESTERN, D. Prefácio: definindo o ecoturismo. In: LINDBERG, K;; HAWKINS, D.E. (eds.). Ecoturismo: um guia para planejamento e gestão. 2. ed. São Paulo: Ed. SENAC SP, 1999.

WU, Y.Y; WANG, H.L.; HO, Y.F. Urban ecotourism: defining and assessing dimensons using fussy number construction. International Journal of Tourism Management, vol.30, issue 06, 2010.

\section{Nota:}

1 "[...] travel and exploration within and around an urban area that offers visitors enjoyment and appreciation of the city's natural and cultural resources, while inspiring physically active, intellectually stimulating and socially interactive experiences; promotes the city's long-term ecological health by promoting walking, cycling, public transportation; promotes sustainable local economic and community development and vitality; celebrates local heritage and the arts; is acessible and equitable to all (Blackstone Corporation, 1996)".

Diôgo da Silva Santos: Universidade Federal da Paraíba, João Pessoa, PB, Brasil.

E-mail: santosdiogo@outlook.com

Link para o currículo Lattes: http://lattes.cnpq.br/3487654453548044

Ligia Maria Tavares da Silva: Universidade Federal da Paraíba, João Pessoa, PB, Brasil.

E-mail: ligiamts@hotmail.com

Link para o currículo Lattes: http://lattes.cnpq.br/4283443117020254

Data de submissão: 27 de abril de 2015

Data de recebimento de correções: 28 de outubro de 2017

Data do aceite: 06 de novembro de 2017

Avaliado anonimamente 